\title{
SENA, SOPHIA, MAGALHÃES: SOBRE A POESIA PORTUGUESA ANTES E DEPOIS DA REVOLUÇÃO DE 74
}

\author{
SENA, SOPHIA, MAGALHÃES: ON \\ PORTUGUESE POETRY BEFORE AND AFTER \\ THE 1974 REVOLUTION
}

Paloma Roriz ${ }^{1}$

\section{RESUMO}

Realizando um breve apanhado da situação da poesia portuguesa a partir do final da década de 1920, fomentada em grande parte por linhas de estratégias de recusa e diálogo com a herança modernista de Fernando Pessoa e da geração de Orpheu, o presente artigo procura refletir como alguns projetos estéticos e ideológicos, operados pelos poetas Jorge de Sena, Sophia de Mello Breyner e Joaquim Manuel Magalhães, apresentam, em seus possíveis pontos de contato e divergência, diferentes formas de articulação crítica entre história, ética e poesia.

PALAVRAS-CHAVE: Poesia portuguesa; ética; história.

\section{ABSTRACT}

With a brief summary of the situation of Portuguese poetry from the end of the 1920's, fomented to a large degree by lines of strategy of refusal and dialogue with the modernist heritage of Fernando Pessoa and the generation of Orpheu, this article seeks to reflect on how some aesthetic and ideological projects, such as those operated by the poets Jorge de Sena, Sophia de Mello Breyner and Joaquim Manuel Magalhães, presented, in their possible points of contact and divergence, different forms of critical articulation between history, ethics and poetry.

KEYWORDS: Portuguese poetry; ethic; history. 
Em seu livro Fernando, Rei da Nossa Baviera, Eduardo Lourenço aponta para um paradoxo da poética pessoana: todos os que já conhecem de cor o verso "o poeta é um fingidor", em geral, não se dão conta de que essa arte poética significava para quem através dele se exprimia o "impossível sonho de uma poesia sem fingimento" (LOURENÇO, 1986, p. 67), ou seja, de um contato entre o homem e a sua verdade. Tal paradoxo talvez seja um ponto de partida interessante para tentar entender alguns aspectos da problemática lançada não só pela obra de Fernando Pessoa como pela geração de Orpheu às gerações de poetas ao longo do século XX. O que vemos entre o final dos anos 1920 e os anos de 1960, aproximadamente, são sucessivas formas de ligação, recusa, diálogo e diferenciação em relação ao legado de Pessoa e do modernismo de Orpheu, bem ilustradas através de inúmeras manifestações teóricas e polêmicas trocadas em torno de questões estéticas, poéticas e ideológicas entre as revistas literárias de cada período, como as revistas Presença, as muitas surgidas com o neorrealismo e os Cadernos de Poesia. Nessa perspectiva, gostaria então de me deter inicialmente no nome de Jorge de Sena - poeta que ocupará um lugar especial na história da recepção da obra de Fernando Pessoa, tanto pela precocidade da sua intervenção, como sobretudo pelo conhecimento que revela ter da poesia e da obra até o momento publicada de Pessoa - e ao seu pensamento poético forjado através da ideia de testemunho.

Quando a revista Presença (1927-1940) se extingue e começa a ganhar força o movimento neorrealista, a literatura portuguesa vive um clima de grande polêmica entre as concepções da "poesia pura" e da "poesia social", que no fundo já representava uma crise do processo modernista iniciado pela geração de Orpheu. Assim, em 1940, entre a extinção da revista Presença e o aparecimento do Novo Cancioneiro (1941), os dois espaços editoriais mais representativos da atmosfera de polemismo presente no quadro da literatura portuguesa daquele momento, ambos girando em torno da questão do entendimento da finalidade artística da poesia, surge em Lisboa, com o propósito de uma superação ética do impasse, ${ }^{2}$ sem abrir mão da diversidade estética, os Cadernos de Poesia (1940-1953), organizados pelos poetas Tomas Kiz, José Blanc e Ruy Cinatti. E vai ser em 1951, à frente da organização da edição da revista, que Jorge de Sena apresenta a nota característica de sua visão testemunhal da expressão poética.

Trazendo o lema A poesia é só uma, porque afinal não há outra, a poesia é então definida como compromisso intencional e relacional: "um compromisso firmado entre um ser humano e o seu tempo, entre uma personalidade e uma consciência sensível do mundo, que mutuamente se definem" (LOPES; SARAIVA, 1996, p. 238). Desse modo, todo ato poético configura um ato de transformação do mundo mediado pela dialética da ação e do conhecimento. A ideia de um compromisso com o seu tempo através da "consciência sensível do mundo" (LOPES; SARAIVA, 1996, p. 238) é importante para perceber a oposição que o autor vai operar entre 
a ideia de testemunho e a de fingimento enquanto paradigma poético. No prefácio de Poesia I, de 1960, Sena afirma:

Se o fingimento é, sem dúvida, a mais alta forma de educação, de libertação e esclarecimento do espírito enquanto educador de si próprio e dos outros, o testemunho é, na sua expectação na sua discrição, na sua vigilância, a mais alta forma de transformação do mundo, porque nele, com ele e através dele, que é antes de mais linguagem, se processa a remodelação dos esquemas feitos, das ideias aceites, dos hábitos sociais inconscientemente vividos, dos sentimentos convencionalmente aferidos. Como um processo testemunhal sempre entendi a poesia. (SENA, 1961, p. 25-26)

A menção a Fernando Pessoa é evidente. Sena denuncia em Pessoa um distanciamento da experiência vivida, a negação da experiência da vida e do seu próprio tempo. A defesa de uma poética do testemunho implica assim a "relação crítica entre poesia e História", articulando o poético a um compromisso ético com o outro e o mundo. É dessa forma que a poética seniana não se exime de participar do seu tempo, de participar atentamente da experiência de sua época. A relação testemunhal com a cultura, movida pelas contextualizações da percepção física, sensível e/ou intelectual forja assim uma das características mais inconfundíveis da poética seniana.

Se pensarmos na obra poética de Sophia de Mello Breyner Andresen, algumas palavras aparecem muito ligadas ao seu universo como, por exemplo, justeza, atenção, rigor. Mas a ideia de um senso testemunhal no sentido evocado por Jorge de Sena não deixa de estar presente, mais especificamente a partir de seu livro Sexto, de 1962, no qual é possível reconhecer uma clara vocação testemunhal e interventiva, com o olhar poético vinculado a uma consciência moral de um "olhar vigilante". O metatexto preliminar do volume da Obra Poética demarca a propósito que a "a poesia é uma moral" realmente "vivida", expressão "de rigor, de verdade e de consciência", misto de "louvor e protesto", "busca de justiça" e diagrama da ordem do mundo. Em sua "Arte poética II", ela nos diz:

Pois a poesia é minha explicação com o universo, a minha convivência com as coisas, a minha participação no real, o meu encontro com as vozes e as imagens. Por isso o poema não fala de uma vida ideal mas sim de uma vida concreta [...]. (ANDRESEN, 2004, p. 189)

Já em um texto datado de 1975, intitulado "Poesia e Revolução", a poeta afirma: "É a poesia que torna inteiro o meu estar na terra. E porque é a mais funda implicação do homem no real, a poesia é necessariamente política e fundamento da política" (ANDRESEN, 1986, p. 75), ao que acrescenta: "Pois a poesia busca o verdadeiro estar do homem na terra e não pode por isso alhear-se dessa forma do estar na terra que a política é" (ANDRESEN, 1986, p. 75). É interessante perceber aqui o nítido distan- 
ciamento em relação às premissas poéticas e artísticas de Fernando Pessoa e da geração de Orpheu, na esteira do "princípio poético" de Edgar Allan Poe, no sentido daquilo que se entendia como uma celebração da liberdade e autonomia da arte e de uma dissociação entre arte e uma função moral, caras ao primeiro modernismo português e ao programa sensacionista, sem qualquer vínculo a compromissos de ordem moral, política ou social. Se lembrarmos as três regras básicas da arte segundo Fernando Pessoa, na terceira ele vai dizer:

A arte não tem, para $\mathrm{o}$ artista, fim social. Tem, sim, um destino social, mas o artista nunca sabe qual ele é, porque a Natureza o oculta no labirinto dos seus desígnios [...]. O artista deve escrever, pintar, esculpir, sem olhar a outra coisa que ao que escreve, pinta, ou esculpe. Deve escrever sem olhar para fora de si. É tão vergonhoso fazer arte moral como fazer arte imoral. (PESSOA, 1993, p. 434)

Cabe ressaltar que Fernando Pessoa é um dos poetas mais evocados pela autora, como podemos notar em muitos poemas de cunho intertextual ao longo de sua obra. Mas o que se percebe claramente, tanto em Jorge de Sena quanto em Sophia, é a forma ambígua e contraditória com a qual os dois vão dialogar com a obra pessoana. Como se ambos fossem procurando caminhos, formas, estratégias para lidar com essa herança modernista. Nesse sentido, é importante salientar que a consciência testemunhal na concepção seniana não implica um dogmatismo de ordem explicitamente ideológica, como irá ocorrer com o posicionamento de poetas neorrealistas, por exemplo. É, antes de mais, uma atitude de lucidez, de independência e compreensão, o que inclusive faz com que integrantes da revista Cadernos de Poesia, entre os quais a própria Sophia, insistam na rejeição de definições como "grupo literário" ou "associação de poetas". Para perceber melhor como tais questões irão se refletir na produção da autora, segue um poema seu intitulado "A casa térrea", do livro O nome das coisas, de 1977, livro muito marcado pela Revolução de 25 de Abril:

Que a arte não se torne para ti a compensação daquilo que não [soubeste ser

Que não seja transferência nem refúgio

Nem deixes que o poema te adie ou divida: mas que seja

A verdade do teu inteiro estar terrestre

Então construirás a tua casa na planície costeira

A meia distância entre montanha e mar

Construirás - como se diz - a casa térrea -

Construirás a partir do fundamento.

(ANDRESEN, 1986, p. 35)

O poema parece se aproximar da poética de testemunho seniana justamente naquilo que pode conter de crítica ao paradigma do fingimento em poesia, do distanciamento em relação ao mundo e sua inteireza: "Que 
a arte não se torne para ti a compensação daquilo que não soubeste ser", verso que aponta em alguma medida para a crítica de Sophia ao fato de que Pessoa se distanciava da experiência comum, era "limpo de vida", "isento de destinos", como encontramos em algumas de suas expressões em textos homenagens ao poeta. A dificuldade com Pessoa se colocaria não tanto pela sua falta de comprometimento político quanto pelo que chamam "a sua ausência à sua própria vida” (SILVA, 2012, p. 120).

Assim, Sophia e Sena enfrentam a dificuldade de se afirmar perante essa herança poética, evitando o extremismo assumido por autores do neorrealismo, tendo que, ao mesmo tempo, aliar uma prática poética própria ao posicionamento político contra a ditadura. Em um artigo acerca do diálogo de alguns poetas com o legado pessoano, Sofia de Sousa Silva toca a questão, lembrando que ambos, Sophia e Sena, se dedicarão

sobretudo a partir da década de 60 , à descoberta de um possível sentido de comunhão para a arte [...]. Apesar de seu papel ativo de resistência à ditadura de Salazar, Sophia e Sena procuram preservar a poesia como um terreno de liberdade, e não fazer dela um instrumento, como entendiam os neorrealistas. Há poemas militantes, mas, de modo geral, não se encontra na obra de qualquer desses dois autores uma ideia de submissão da arte a um projeto político. (SILVA, 2012, p. 121)

Enquanto estratégia de pensamento e de atividade de escrita, a poética do testemunho aponta para a "relação crítica entre poesia e História, e envolvendo o poético com um compromisso ético com o outro e o mundo", como afirma Ida Alves (2006, p. 35) no artigo "Jorge de Sena e a ética da poesia: um testemunho para os poetas de 70 ”. Não se eximindo de participar de seu tempo, a poética seniana forjaria um discurso poético marcadamente político, no espectro mais amplo da palavra, em que o testemunho surgiria como uma "tarefa primordial". É esse posicionamento de Sena que o fará "figura tutelar" para alguns dos poetas que iniciaram sua trajetória na década de 70 :

Essa perspectiva mais se amplia para os jovens poetas em pleno acirramento da guerra colonial, já fartos de uma ditadura que corroera até o osso o corpo da nação, moldando uma sociedade corrompida e estagnada. Em poetas como Joaquim Manuel Magalhães e João Miguel Fernandes Jorge nota-se esse olhar questionador, a mesma coragem em rever a História, enfrentando-a, confrontando-a. Neles está em eco o tom irônico, por vezes agressivo e/ou arrogante seniano e a necessidade de não calar, de não entrar em conluios. (ALVES, 2006, p. 35)

E é na esteira do modo particular com o qual Jorge de Sena conduzia seu trabalho crítico que podemos reconhecer sua ressonância no papel crítico e ensaístico exercido por Joaquim Manuel Magalhães ao longo das décadas de 70 e 80, no sentido da defesa de uma "ética da poesia e o desejo de renovação de comportamentos estéticos” (ALVES, 2006, p. 37). 
Tendo tal perspectiva como pano de fundo, gostaria de propor uma breve leitura contrastiva entre dois textos exemplares acerca da relação do exercício poético e sua dimensão ético/política: o primeiro, de Sophia de Mello Breyner, lido por ocasião da entrega do Prêmio da Poesia da Sociedade Portuguesa de Escritores (ANDRESEN, 2014, p. 122), de 1964, e o segundo, intitulado "Uma geração dessatisfeita", de Joaquim Manuel Magalhães, de 1981. O que talvez seja interessante é perceber os dois textos como produções realizadas anos antes e depois da Revolução de 74 . Podemos então pensar, embora de forma abreviada, dados os limites deste artigo, acerca do que estaria em jogo na "virada" ocorrida no cenário da poesia portuguesa nesse período, tanto no sentido histórico-político quanto estético. Seguem alguns trechos do texto de Sophia:

Sempre a poesia foi para mim uma perseguição do real. Um poema foi sempre um círculo traçado à roda duma coisa, um círculo onde o pássaro do real fica preso. E se a minha poesia, tendo partido do ar, do mar e da luz, evoluiu, evoluiu sempre dentro dessa busca atenta. Quem procura uma relação justa com a pedra, com a árvore, com o rio, é necessariamente levado, pelo espírito de verdade que o anima, a procurar uma relação justa com o homem. (...)

E é por isso que a poesia é uma moral. E é por isso que o poeta é levado a buscar a justiça pela própria natureza da sua poesia. E a busca da justiça é desde sempre uma coordenada fundamental de toda a obra poética. (...)

A moral do poema não depende de nenhum código, de nenhuma lei, de nenhum programa que lhe seja exterior, mas, porque é uma realidade vivida, integra-se no tempo vivido. E o tempo em vivemos é o tempo duma profunda tomada de consciência. (ANDRESEN, 2004, p. 155-156)

No texto, a ideia de "justiça" ganha especial peso e aparece enquanto entendimento da relação com o próprio mundo, e nele a relação com o homem, na qual a poesia se presta também a veículo e catalisador de uma "profunda tomada de consciência" de seu tempo. Não é difícil perceber nessas afirmações uma clara ressonância do pensamento testemunhal de Jorge de Sena. Já nos primeiros números dos Cadernos de Poesia, encontramos formulações de princípios poéticos de cunho humanista nos quais a poesia seria definida como "compromisso intencional e relacional" entre o homem e o seu tempo, daí a procura de uma atitude de lucidez e independência desvinculada de qualquer tipo de ligação mais explícita a programas políticos. São todos elementos que se coadunam com o teor da fala de Sophia, quando diz: "A moral do poema não depende de nenhum código, de nenhuma lei, de nenhum programa que lhe seja exterior".

Vale lembrar que a escrita de Sophia procura criar um diálogo com as tradições da modernidade e do romantismo, o que podemos veri- 
ficar tanto na forma com a qual sua poética se relaciona com a obra pessoana, como apontado anteriormente, quanto em sua busca por um sentido unitário do dizer, caro aos românticos. Nesse sentido unitário se inscreveria, portanto, um entendimento de coesão e correspondência entre todas as coisas, inclusive as de ordem política, social e moral. Caberia ressaltar também que a inclinação de Sophia ao ético em poesia não se restringiria à mera retórica: a poeta pertenceu ao movimento de resistência ao regime salazarista, além de outras organizações de resistência e antes mesmo do 25 de abril integrou a Comissão Nacional de Socorro aos Presos Políticos. Posteriormente, no ano de 1975, viria a ser eleita deputada na Assembleia Constituinte, filiada ao Partido Socialista. Nesse contexto, podemos então pensar em alguns poemas da escritora de teor mais marcadamente político como, por exemplo, o de título "25 de abril":

Esta é a madrugada que eu esperava

O dia inicial inteiro e limpo

Onde emergimos da noite e do silêncio

E livres habitamos a substância do tempo

(ANDRESEN, 1986, p. 25)

Ou ainda "Revolução":

Como a casa limpa

Como chão varrido

Como porta aberta

Como puro início

Como tempo novo

Sem mancha nem vício

Como a voz do mar

Interior de um povo

Como página em branco

Onde o poema emerge

Como arquitectura

Do homem que ergue

Sua habitação

(ANDRESEN, 1986, p. 26)

João Barrento, em um artigo sobre a poesia portuguesa produzida após a Revolução de 74, alude a uma imagem de Theodor Adorno que tomo aqui de empréstimo: Barrento diz que na imagem de Adorno, o poema é como um relógio de sol em cujo quadrante se podem "ler as mais leves oscilações do tempo e dos tempos, as vibrações anímicas de um sujeito" (BARRENTO, s/d), assim como as zonas de sombra e luz de um pensa- 
mento histórico. Com isso, João Barrento enfatiza que o que lhe interessa é tentar perceber em que medida as expressões poéticas de uma determinada época podem desenhar em nosso horizonte de leitura a configuração de um tempo. Tempo que, no que se refere à sua projeção no poema, "tanto pode corresponder a um tempo histórico bem específico" (BARRENTO, $\mathrm{s} / \mathrm{d}$ ) (como no caso dos dois poemas de Sophia), como "remeter para uma atmosfera mais difusa". De fato, o momento histórico no qual os poemas acima foram escritos diz de um profundo sentimento de esperança, entusiasmo e idealização em relação ao futuro, sentimentos aliados ainda a uma franca confiança na palavra poética e na "espessura discursiva do poema" (MARTELO, 2007, p. 86), numa expressão de Rosa Maria Martelo, o que de algum modo se reflete na força de algumas palavras empregadas em ambos, como início, inteireza e integridade, além de habitação, e que talvez se aglutinem em uma só, a palavra fundamento, que irá aparecer no poema "A casa térrea", citado anteriormente.

Em seu livro Vidro do mesmo vidro - Tensões e deslocamentos na poesia portuguesa depois de 1961, Martelo ressalta algumas características em comum a nomes como Carlos de Oliveiro, Mário Cesariny, Jorge de Sena, Eugénio de Andrade, Herberto Helder, Ruy Belo, autores da Poesia 61 e a própria Sophia Andresen. Segundo a autora, apesar da grande diversidade apresentada por tais escritores, todos refletiriam em alguma medida formas particulares de diálogo com a tradição modernista, através de diferentes articulações com o trabalho de escrita, numa "rede de cumplicidades estéticas", entre elas: "a recusa do lirismo expressivista e a contenção do derramamento sentimental; a valorização da imagem e da metáfora; uma escrita metadiscursiva; a busca de vigor verbal aliada a uma forte consciência da emergência textual da poesia" (in MAFFEI, 2008, s/p). Contudo, a partir dos anos 1970, com o surgimento de poetas como Joaquim Manuel Magalhães, por exemplo, Martelo aponta que terá início uma problematização desse tipo de perspectiva em poesia:

No entanto, é inegável que então se começará a assistir a um progressivo investimento naquilo que Joaquim Manuel Magalhães viria a chamar, nos inícios da década de 80, a 'tensão emocial' do poema. Alguma poesia irá torna-se progressivamente mais transparente, procurando dizer de forma mais realista uma experiência do mundo que antes o poema procurava preferencialmente exibir, ou somatizar, como forma, e o discurso poético irá renovar-se muitas vezes pela experimentação de uma escrita no cruzamento entre o lírico e o narrativo, entre a poesia e a prosa. (in MAFFEI, 2008, s/p)

Interessante aqui é perceber que, para os autores citados por Martelo, o poema cumpriria um papel de contraponto positivo, "como se a poesia respondesse ao mundo que recusa, contrapondo-lhe o furor da sua linguagem e o poder epifânico da metáfora e da imagem poética" (in MAFFEI, 2008, s/p). É o que depreendemos dos versos de Sophia já mencionados, em que o poema surge como forma de inscrição no presente, num ponto de coincidência com o momento histórico, caso do " 25 de Abril”. 
Já o que irá revelar o trabalho de escrita de alguns autores surgidos após a Revolução de 74 será justamente certa descrença na possibilidade dessa convergência, além de uma desvalorização do poder da palavra poética. Ocorre que, passados alguns anos do 25 de Abril, fato é que muitas ilusões e crenças caíram por terra, abrindo para muitos uma profunda consciência de desencanto: "Pese embora a dissolução da ditadura política, o sistema endemicamente conservador da sociedade portuguesa continua sinistro" (SANTOS, 2014, p. 143). Vejamos algumas passagens do texto "Uma geração dessatisfeita" do poeta Joaquim Manuel Magalhães, publicado em 1981. Segue o início:

Numa época de declarações de fé poéticas, de tentativas de novos movimentos e de buscas de fazer passar por vanguarda um seguidismo melhor ou pior disfarçado das efectivas vanguardas de princípio de século (tanto faz seguir Aristóteles como Duchamp), é importante encarar uma certa dimensão da poesia: o seu curso não tem, apesar de repetidas visões milenaristas. Mas, como esta, ela tem de arrancar propostas que sejam centrais por se aproximarem da possibilidade de promover um confronto com o real que existe. E quem diz poesia, diz de uma vez por todas as outras artes.

Os poetas, sujeitando-se à penúria mental de políticos que se diziam ligados a algumas ideologias heróicas, tornaram-se lugares vazios de exemplo. (...)

Há cada vez mais uma revolta que não sabe que palavras usar porque lhe estragaram os sentidos de maior sedução: socialismo, justiça, igualdade. Sobretudo porque lhe retiraram a liberdade de poder instituir realmente o seu desejo de transformação do real. (...)

O acto poético é como a coragem de ter entrado com tanques pelo totalitarismo, ocupado postos de comunicação e aeroportos, inundado de euforia as ruas, promovido a paz, como no 25 de Abril entre nós. Mas não pode parar para deixar que grupos matreiros acanalhem a conquista da esperança. (MAGALHÃES, 1981, p.365-366-368)

Um ponto relevante aqui talvez seja o de perceber que a proposição crítica de Joaquim Manuel Magalhães, não sem significativos antecedentes na poética do testemunho de Jorge de Sena, estava nesse momento buscando abrir espaços para novas vozes que surgiam na cena literária portuguesa, à qual inclusive ele pertence, daí uma declarada combatividade em seu discurso na busca por abertura e criação de novos paradigmas. Recuperando o texto de Sophia acerca da relação entre poesia e moral, percebemos que o sentido do real ali comparece sobretudo como instância a ser apreendida e capturada, como indica a afirmação "Sempre a poesia foi para mim uma perseguição do real” (grifo nosso). Em Magalhães, diferentemente, o real é apresentado como algo a ser confrontado, real em andar térreo histórico-político assim como artístico incontornável: não mais o de 
uma idealização estético-filosófica ou programática como projeto e desejo possível de futuro, mas o de uma sobriedade dada em contrapartida ao desamparo de certas palavras que, "estragadas", já não respondem. A ideia vai aparecer não só no texto crítico de Magalhães, como também em sua poesia, por exemplo, no poema "Princípio", surgido na virada dos anos 70 para os anos 80, do livro Os dias, pequenos charcos, de 1981:

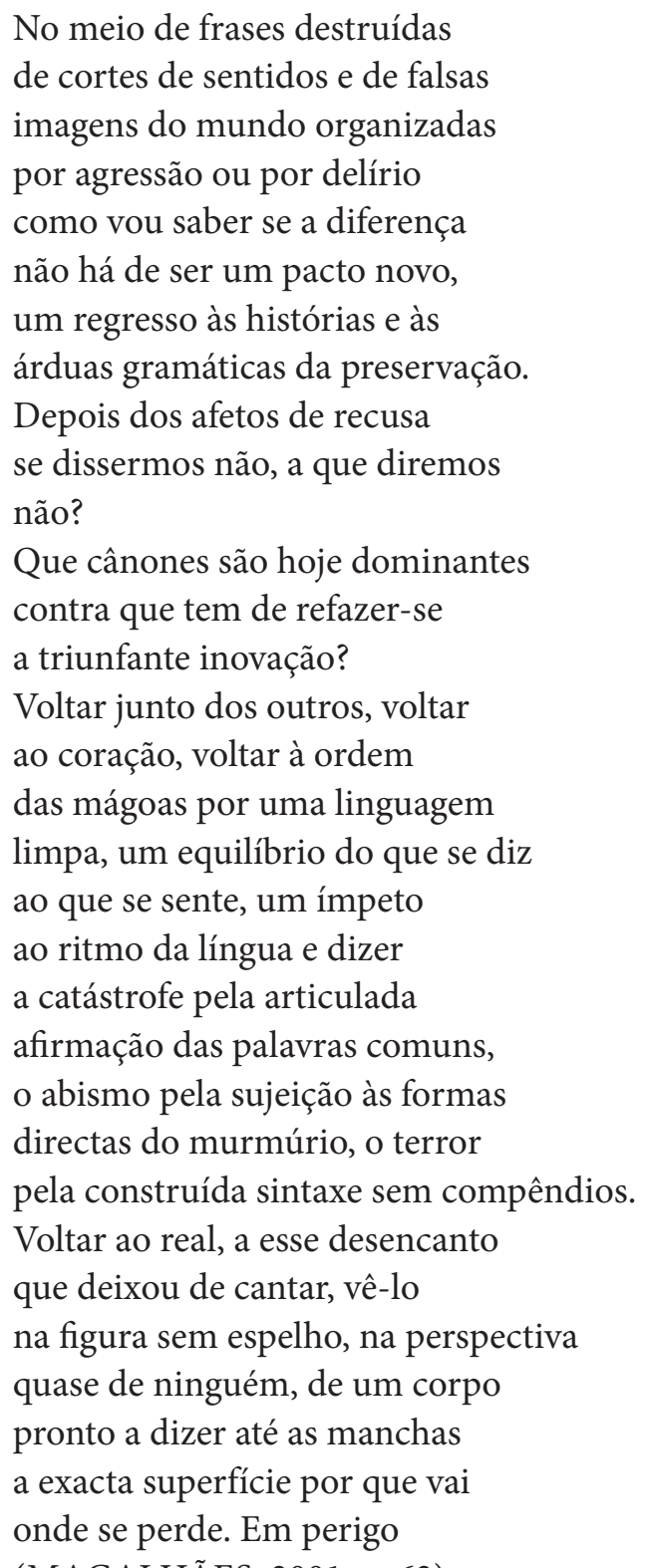

(MAGALHÃES, 2001, p. 62)

O posicionamento de Magalhães contribui para aquilo que seria entendido por alguns como uma denúncia cáustica do "esgotamento do ethos modernista", confirmando assim uma situação de "instabilização do espaço poético-crítico" (SANTOS, 2014, p. 143) no quadro da poesia portuguesa daquele momento. Teríamos então a ideia de uma dupla desilusão: por um lado, a desilusão com a herança da modernidade, expressada pela descrença numa "expectativa de sublimação pela arte" (GARRAMUÑO, 2012, p. 68) e, por outro, a desilusão diante das fissuras, problemas e contradições da sociedade contemporânea. É assim que, diante da aguda cons- 
ciência desse impasse, alguns poetas como João Miguel Fernandes Jorge, Adília Lopes e o próprio Joaquim Magalhães, entre outros, buscam se situar num lugar crítico face ao poético, tentando responder a questões como: "Por quê e para quê escrever ainda hoje? Como ler a literatura que os formou? Que cultura é essa que os cerca? Como falar deste tempo contemporâneo, presente de um passado que não se pode esquecer?" (ALVES, 2007, p. 40). Talvez, nesse sentido, não por acaso o poema de Magalhães traga o significativo título de "princípio", quando o retorno ao real, ao coração, ao outro, ao comum, a um "equilíbrio do que se diz ao que se sente", pode significar também a abertura e inscrição de uma nova ética em poesia.

\section{REFERÊNCIAS BIBLIOGRÁFICAS}

ALVES, Ida. Jorge de Sena e a ética da poesia: um testemunho para os poetas de 70. In: Jorge de Sena: Ressonâncias e Cinquenta Poemas (Into e org. Gilda Santos). Rio de Janeiro: 7Letras, 2006.

ANDRESEN, Sophia de Mello Breyner. O nome das coisas. Lisboa: Edições Salamandra, 1986.

Poemas escolhidos. Seleção de Vilma Arêas. São Paulo: Companhia das Letras, 2004.

. Livro sexto. Lisboa: Assírio \& Alvim, 2014.

BARRENTO, João. Um Quarto de Século de Poesia Portuguesa. In: Revista Semear n. 4, s/d. Disponível em: http://www.letras.puc-rio.br/ unidades\&nucleos/catedra/revista/4Sem_19.html [Acesso em: 14/08/2016]

GARRAMUÑO, Florencia. A experiência opaca: literatura e desencanto. Rio de Janeiro: EdUERJ, 2012.

LOPES, O.; SARAIVA, A.J. História da Literatura Portuguesa. 17º Edição. Porto: Porto Editora, 1996.

MAGALHÃES, Joaquim Manuel. Dois crepúsculos - Sobre poesia portuguesa actual e outras crônicas. Lisboa: Relógio D’água, 1981.

Alta noite em alta fraga. Lisboa: Relógio D’água, 2001.

MAFFEI, Luis. De poesia e outras estrofes: entrevista com Rosa Maria Martelo. In: Pequena Morte blog, Ed.\#11, em 12/05/2008. Disponível em: http://www.pequenamorte.net/para-refenciar-a-poesia-seis-perguntas-para-rosa-maria-martelo/\#.V3EufnhDDe [Acesso em: 02/09/2017]

MARTELO, Rosa Maria. Vidro do mesmo vidro - Tensões e deslocamentos na poesia portuguesa depois de 1961. Porto: Campo das Letras Editores, S.A., 2007.

PESSOA, Fernando. Obras em prosa. Rio de Janeiro: Ed. Nova Aguilar, 1993. 
SANTOS, Cristina F. Dançando sobre os destroços da sua imagem: desencanto e trangressão face ao discurso crítico dos anos 70. In: Crítica de poesia: tendências e questões (org. Celia Pedroa, Ida Alves, Nuno Júdice). Rio de Janeiro: 7Letras, 2014.

SENA, Jorge de. Poesia I. Lisboa: Edições 70, 1961.

SILVA, Sofia de Sousa. Ruy Belo: harmonia de forças opostas. In: Revista FronteiraZ. São Paulo, n.9, dez., 2012.

Recebido para publicação em 21/11/2017

Aprovado em 03/02/2018

\section{Notas}

1 Doutoranda na Universidade Federal Fluminense, Programa de Pós-Graduação em Estudos de Literatura. Mestre em Estudos Lusófonos pelo Departamento de Estudos Ibéricos e Latino-americanos na Université Sorbonne Nouvelle - Paris 3. Bolsista CNPq.

2 Sobre o caráter independente dos Cadernos de Poesia: “O carácter antológico e independente decorre de uma consciência superativa face ao polemismo protagonizado por presencistas e neorrealistas, traduzido na oposição irredutível entre 'poesia pura' e poesia social', em que a literatura portuguesa se cindia na viragem da década" (LOPES; SARAIVA, 1996, p 236). 